\title{
El papel de la flexibilidad laboral en el empleo chileno
}

\section{I}

\section{ntroducción}

En los últimos veinte años la economía Chilena experimentó cambios en diferentes niveles. Ejemplo de ello son las actividades productivas que dejaron de ser sólo para el mercado interno y que se esperaba fueran incorporadas con éxito en los mercados globalizados (Espinosa,2000). De igual manera en el interior de las empresas, pero relacionado con las relaciones laborales, se presentaron cambios en diferentes direcciones, mismas que tuvieron como escenario la flexibilidad.

Según análisis de expertos internacionales Fröble, Heinrichs y Kreye (1980), Piore y Sabel (1984), para comprender económica y sociológicamente al mundo productivo de fines de siglo es necesario considerar la revolución tecnológica y otros procesos de racionalización productiva y organizacional, por ejemplo: los encadenamientos y la externalización de partes y procesos, las modalidades de jornada parcial, la periodicidad de entrada y salida de la fuerza de trabajo secundaria, la subcontratación y el trabajo eventual, entre otros.

Bajo este contexto, y contrario a lo que se pensaba sucedería a finales del siglo XIX con el crecimiento económico (reducción de la pobreza, de las desigualdades sociales, conflictos sociales, etc.), lo que hoy se presenta es una declinación de la actividad organizativa del mundo laboral. Ejemplo de lo anterior es la débil fuerza que pudiera tomar el sindicato en Chile cuando pasa de un contexto político a un contexto social, un sistema de relaciones que no alcanza los estándares necesarios que le doten de seguridad en el empleo al trabajador y posturas empresariales con defensas intransigentes ante la legislación laboral. Las dimensiones por analizar son muchas, pues el sistema productivo

* Investigadora del Departamento de Estudios del Pacífico de la Universidad de Guadalajara. que se ha puesto en marcha en Chile sugiere diferentes análisis. Sin embargo, serán tres las variables que se discutirán en este documento: las flexibilidades laboral, contractual y sindical.

\section{Flexibilidad laboral}

La flexibilización ${ }^{1}$ en Chile muestra características parecidas a las que se presentan en el contexto latinoamericano, que ha apostado al escenario globalizado. En este caso la flexibilidad para contratar y despedir es sinónimo de flexibilidad numérica. Ante la falta de modernización en las relaciones laborales, Chile se encuentra en desventaja en cuanto a condiciones de competitividad internacional, mismas que no permiten el aumento en la productividad y con ello la falta de estándares de calidad tanto en los productos fabricados como en los empleos creados. Además, las condiciones estructurales en el nuevo paradigma productivo dificultan la organización, ejemplo de ello son estrategias como: empleos atípicos, precarios y temporalidad (Espinosa,2000).

Otra de las variables de la flexibilidad son las formas de pago distintas a las del tradicional sueldo o salario fijo y por períodos mensuales (Vergara del Río, 2000). Ejemplo de estas son: bonos, incentivos, premios o cualquier beneficio pagado por el empleador al trabajador a condición de un incremento a su productividad. El carácter legal que adquieren estas nuevas formas de remuneración quedan registradas en la Dirección del Trabajo, donde se acuerdan "los benéficos asociados al aumento de la productividad" (Vergara del Río, 2000). Así los contratos colectivos vigentes señalan cláusulas que determinan al trabajador como sujeto a estándares de productividad requeridos por la empresa.

Aunada a la anterior se encuentra la productividad como mecanismo de flexibilización; su fundamento se encuentra en 
la economía globalizada en la que el país chileno participa (Vergara del Río). De manera que empresa y competitividad son dos conceptos que dependen de la capacidad de poner productos en el mercado. Así, es como se engarzan las estructuras de los sistemas laborales donde hoy en día el trabajador queda pendiente de las empresas en espera de una mejora en el nivel de remuneraciones involucrados en la producción. Como resultado se tiene que la incorporación de la productividad es un elemento de definición del salario que da como solución remuneraciones variables, lo que atenta contra la certidumbre y fijeza del mismo. En este orden de cosas es importante destacar que la negociación colectiva, en Chile, involucra a un bajo porcentaje de trabajadores (10 por ciento de los asalariados aproximadamente). De esta forma, la gran mayoría de los trabajadores pacta sus remuneraciones en el contrato individual y probablemente también se incluyan formas de remuneración por productividad. En la negociación individual el trabajador es más vulnerable y tiene escaso poder negociador, aceptando, por regla general, las condiciones predefinidas por el empleador.

\section{Flexibilidad contractual}

Relacionadas con la flexibilidad contractual, en el nuevo paradigma productivo que se ha implementado actualmente en Chile, se encuentran las relaciones entre industrias y empresas de servicios cuya razón se centra en la subcontratación en cadena. 42 por ciento de las industrias en general subcontrata la actividad económica principal; a su vez 16 por ciento ha sido subcontratada por otros (ENCLA,
1999). Esto se convierte en una problema serio porque, a medida que la subcontratación se comporta de esta manera, las condiciones de trabajo se van modificando hasta alcanzar la flexibilización así como la precarización en diferentes sentidos (salarial, sindical, horaria, numérica) como respuesta a las fluctuaciones del mercado (Espinosa,2000).

En este contexto de globalización, también Chile ha experimentado cambios importantes en la negociación colectiva, lo que encuentra su justificación en las nuevas formas de producción y en la organización de las empresas que se han instalado alrededor del mundo (Dinamarca, 2000). Las formas atípicas de contrato que han surgido en los últimos años, mismas que se han conceptualizado como formas de precarización del empleos, son: externalización de procesos con la subcontratación de partes o procesos completos fuera de la empresa que designa el empleo, la existencia de una masa flotante de trabajadores, el trabajo a domicilio, y el aumento del número de trabajadores eventuales o de temporada. Éstas no tienen siempre su origen en las limitaciones legales, sino en la diversificación y/o segmentación productiva (Espinosa,2000).

\section{Flexibilidad sindical}

Respecto a la flexibilidad sindical, son diferentes las empresas modernas que han puesto en marcha estrategias para llegar a acuerdos con la fuerza laboral organizada en sindicatos, pero la institucionalidad laboral en este país es débil, de tal manera que los mecanismos de participación son escasos y la capacidad de negociación es baja (idem). Se cree que ante el predominio de una postura empresarial que 
sostuvo una defensa intransigente de la legislación laboral que se generó bajo un régimen militar, se dejó de analizar la necesidad de avanzar hacia la generación de un marco normativo que correspondiera a las realidades que vive el país chileno, como las transformaciones de la inserción acelerada durante la última década.

La flexibilidad sindical, al menos en el caso chileno, se puede discutir desde estadísticas de crecimiento y evolución sindical: presencia sectorial y regional; tipos de sindicatos; evolución de las federaciones y confederaciones, y perfil de los dirigentes sindicales. Los escenarios y actores están sujetos a los ajustes estructurales y ajustes de roles. En este país se han producido algunos procesos iniciados desde fines de la década de 1970 "básicamente las políticas de ajuste estructural puestas en práctica por el régimen militar, cuya consolidación se produjo a mediados de los ochenta, después de la crisis de 1981-1982" (Espinosa,2000). Estas políticas facilitaron la apertura de la economía con bastante anticipación, si se le compara con lo ocurrido en otros países latinoamericanos que iniciaron sus procesos de ajuste más tarde. De hecho, las políticas implementadas en otros países con posterioridad al caso chileno (Argentina, Brasil, México, Colombia y otros), la radicalidad y velocidad de las medidas tomadas, incluidas las reformas a la legislación laboral, fueron más cautelosas sobre los efectos sociales que en Chile.

En el contexto chileno, en lo que se refiere al ámbito específico de lo laboral para el logro de la flexibilidad del mercado de trabajo, el ajuste neoliberal permitió el despido sin expresión de causa y restringió con diversas disposiciones la efectividad de la acción colectiva sindical -entre otras: el derecho a huelga y la prohibición para formar centrales sindicales. Históricamente, el sindicalismo es una forma de organización asociada más fuertemente a la industria extractiva y manufacturera, y sólo por extensión se fue transformando en un derecho para las otras actividades económicas. La asociación sindicalismo - industria, ha marcado el perfil del sindicalismo chileno, y es así que en
1995 casi un tercio ( 27.43 por ciento ) de los sindicatos están radicados en dicha rama de actividad económica (Espinosa,2000).

En síntesis, la década muestra que las ramas de mayor tasa de sindicalización tienden a disminuir y viceversa. Las ramas que están sobre la tasa promedio nacional, que es de 19.3 por ciento en orden ascendente, son: comercio (20.1); industria (28.3); transporte (40.9); electricidad, gas y agua (49) y minería (65.7). Las ramas que están bajo el promedio nacional, en orden descendente, son: servicios financieros (14.2); agricultura (13.5); construcción (13.4) y finalmente servicios sociales, comunales y personales, que está en el mínimo de la escala (8.8) (ENCLA,2000).

\section{Conclusión}

En el debate chileno e internacional han predominado nociones sobre el ajuste realizado en el terreno laboral, el inevitable ajuste como respuesta a la crisis y adaptación a las nuevas condiciones económicas y sus virtudes respecto de la estabilización y el crecimiento. Se trata, en los años noventa, de hacer un "ajuste social" al exitoso ajuste económico que se ha realizado.

Hoy en día la relación entre los actores: (sindicatos y empresarios, y entre estos y el Estado) está mediatizada por el discurso del mercado, que se transforma en una entidad reguladora externa e inmanejable por los actores. Incluso, en algunas legislaciones de países donde se ha analizado el Código civil, los que antes se llamaban trabajadores hoy día se llaman "mercado laboral". La categoría mercado de trabajo es una categoría económica para tipificar un fenómeno de demanda y oferta de mano de obra, en tanto trabajadores es una categoría social que no apunta a lo mismo, porque el trabajador es un sujeto social dotado de derecho y portador de una cultura y, por ello, con capacidad de modificar su entorno. En este contexto, el sindicalismo puede debatir sobre el mercado, no para combatirlo como un factor intrínsecamente perverso (como pareciera desprenderse del pronunciamiento público), sino para protegerse de los efectos que pudiera 
presentar una política de mercantilizar lo que no se puede mercantilizar, sino negociar socialmente las condiciones de empleo y salario.

El punto central frente a estas tendencias de flexibilización del empleo no es impedir su ocurrencia, sino, por el contrario, en la medida que sea posible generar una equiparación de condiciones salariales, previsionales y de seguridad en el trabajo, similares al empleo típico. En las experiencias internacionales se advierte que, mirado este proceso a largo plazo, es posible que aparezcan algunas disfuncionalidades, particularmente las que derivan de las mayores exigencias de calidad y productividad. En medio de esta fluidez y movilización del mercado de trabajo, cuyas ventajas económicas y empresariales se han descrito anteriormente, será posible observar comportamientos sociológicos del sujeto trabajador generados como resultado de la inestabilidad permanente del empleo.

\section{Nota}

1 Por flexibilizar se ha entendido desregular al máximo, para permitir que sea exclusivamente el mercado el que defina las cuestiones centrales de las relaciones de trabajo. Esta postura niega, de alguna manera, la concepción de la existencia de derechos laborales que ha estado en la base del desarrollo legislativo nacional y normativo internacional desde la creación de la OIT. La negación del derecho ha dado paso también a una postura radical de protección al derecho y ni una ni otra alternativa permite a los actores abrir un nuevo campo de conversaciones, en el que podrían encontrase mayores consensos acerca de qué y cómo es necesario proteger (Espinosa,2000).

\section{Fuentes}

Dinamarca R., Cristian "Reflexiones sobre la negociación colectiva en Chile", Cuaderno de investigación núm. 4, 2000.

Espinosa Malva, "Tendencias sindicales: análisis de una década”. Departamento de Estudios, Dirección del Trabajo, 1997.

http://www.dt.gob.cl/estudios/nomlab.doc

Espinosa Malva, "Chile relaciones laborales para el siglo XXI", Temas Laborales, Núm. 14,1997

http://econopappers.hhs.se/paper/edjcecauch/91.htm http://www.dii.uchile.cl/cea

http://www.dt.gob.cl/comunica/encla

http://www.dt.gob.cl/estudios/temas10.htm

Riquelme G. Verónica," El tiempo de trabajo", Temas Laborales núm 11., 2000.

Vergara del Río G. Mónica, "Productividad, salarios y negociación colectiva", Temas Laborales, núm.10., Chile,

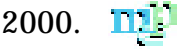

